IZA DP No. 10258

Who Runs? Honesty and Self-Selection into Politics

Sebastian Fehrler

Urs Fischbacher

Maik T. Schneider

October 2016 


\title{
Who Runs? Honesty and Self-Selection into Politics
}

\author{
Sebastian Fehrler \\ University of Konstanz \\ and IZA
}

Urs Fischbacher

University of Konstanz

and Thurgau Institute of Economics

\author{
Maik T. Schneider \\ University of Bath
}

\section{Discussion Paper No. 10258 \\ October 2016}

\author{
IZA \\ P.O. Box 7240 \\ 53072 Bonn \\ Germany \\ Phone: +49-228-3894-0 \\ Fax: +49-228-3894-180 \\ E-mail: iza@iza.org
}

Any opinions expressed here are those of the author(s) and not those of IZA. Research published in this series may include views on policy, but the institute itself takes no institutional policy positions. The IZA research network is committed to the IZA Guiding Principles of Research Integrity.

The Institute for the Study of Labor (IZA) in Bonn is a local and virtual international research center and a place of communication between science, politics and business. IZA is an independent nonprofit organization supported by Deutsche Post Foundation. The center is associated with the University of Bonn and offers a stimulating research environment through its international network, workshops and conferences, data service, project support, research visits and doctoral program. IZA engages in (i) original and internationally competitive research in all fields of labor economics, (ii) development of policy concepts, and (iii) dissemination of research results and concepts to the interested public.

IZA Discussion Papers often represent preliminary work and are circulated to encourage discussion. Citation of such a paper should account for its provisional character. A revised version may be available directly from the author. 


\section{ABSTRACT}

\section{Who Runs? Honesty and Self-Selection into Politics*}

We examine the incentives to self-select into politics and how they depend on the transparency of the entry process. To this end, we set up a two-stage political competition model and test its key mechanisms in the lab. At the entry stage, potential candidates compete in a contest to become their party's nominee. At the election stage, the nominated candidates campaign by making non-binding promises to voters. Confirming the model's key predictions, we find in the experiment that dishonest people over-proportionally self-select into the political race; and that this adverse selection effect can be prevented if the entry stage is made transparent to voters.

JEL Classification: C92, D71, D83

Keywords: candidates, elections, campaigns, primaries, contest, voting, political economy, experiment, lying aversion, self-selection, cheap talk

Corresponding author:

Sebastian Fehrler

University of Konstanz

Box 131

78457 Konstanz

Germany

E-mail: sebastian.fehrler@uni-konstanz.de

\footnotetext{
* We would like to thank Alessandra Casella, Andy Eggers, Dirk Engelmann, Jon Fiva, Francesco Giovannoni, Volker Hahn, Niall Hughes, Aniol Llorente-Saguer, Guido Schwerdt, Ireneaus Wolff and participants at "Political Economy: Theory meets Empirics" workshops in Konstanz and Bath and seminars in Konstanz and Hamburg for helpful comments. All remaining errors are our own.
} 
"The aim of every political Constitution, is or ought to be, first to obtain for rulers men who possess most wisdom to discern, and most virtue to pursue, the common good of society; ...” (James Madison)

“An honest politician is an oxymoron.” (Mark Twain)

\section{Introduction}

Most political systems grant their leaders extensive powers and thus many far-reaching decisions are shaped by their virtues, or lack thereof. Therefore, it is of utmost importance to select politicians who, when in power, will advance the common good. However, as public opinion surveys from different countries show, many people believe that the actual selections in their countries do not meet this goal. Quite the contrary, a widely shared perception is that most politicians are dishonest and have low ethical standards. ${ }^{1}$ The Economist (Sep 10, 2016 issue) even comes to the conclusion that we might have entered an era of "post-truth politics". This is puzzling as it suggests that voters elect politicians who they believe to be dishonest while at the same time several studies suggest that honesty and trustworthiness are candidate characteristics that are important to voters (e.g., Mondak and Huckfeldt, 2006). Why would they do that? A reason might be that the pool of candidates, i.e. the voters' choice set, is mainly populated by dishonest people and voters have no choice in this dimension. Making things even more complicated for voters, dishonest candidates typically try to appear honest by mimicking honest candidates' behavior in the election campaign.

Consequently, how well general elections can select good leaders depends on the quality of the candidates in the electoral race and the information available to voters. In almost all democratic systems the candidates are preselected to stand for election in some process, typically within the large political parties. Therefore, the parties' internal preselections play a major role for the later choice options and outcomes in the general election. A

\footnotetext{
${ }^{1}$ A 2015 Gallup survey for the U.S., for example, shows that from a list of 21 professions Members of Congress receive the next to lowest ratings on perceived honesty and ethical standards, undercut only by lobbyists (see Figure A1 in the Appendix).
} 
prominent example for such preselection institutions are the primaries in the U.S., where politicians compete to be the candidate of either the Democrats or the Republicans in an upcoming election. Depending on media scrutiny, these contests can be more or less transparent to voters with respect to the resources that potential candidates invest to win their party's nomination.

In this study, we investigate a key mechanism that is at play in the preselection phase: self-selection. We show theoretically and in a lab experiment that different incentives for honest and dishonest people to enter the race and to invest resources to win the nomination can strongly influence the candidate pool and the election outcome.

We consider a two stage political process, where at the first stage two political parties select a candidate to stand for election against the candidate of the other party in the second stage. The candidate receiving a majority of votes in the election becomes the elected leader and decides on how to employ the resources that come with the office for her own private or the electorate's benefit. Before voters cast their votes, candidates make campaign promises on how much of the resources they will pass on to the voters.

While a theoretical analysis based on the traditional assumption that candidates are completely selfish suggests that they will promise anything to get elected and once in office maximize their private gains (e.g., Alesina, 1988), it has recently been demonstrated by Geng et al. (2011) and Corazzini et al. (2014) that campaign promises are not just cheap talk even in one-shot interactions. Instead, most subjects in these experiments care about the deviation of their actions in office from their promises at the election stage. While these studies provide important insights into the election stage, they do not investigate the processes that determine the candidate pool. To address this important aspect, we focus on self-selection into politics. More precisely, we tackle the question whether honest or dishonest candidates are more likely to stand for election under different entry regimes. At the preselection stage of our model, in each of the two parties, two politicians compete for candidacy in the general election. We interpret the investments in the contest as reflecting the vast resources in time and money that candidates spend, e.g. in the U.S. primaries. Regarding the information of the voters in the general election, we consider two regimes: the 'transparent entry contest', where voters can observe how much has been invested at 
the preselection stage by each candidate, and the 'opaque entry contest', where voters receive no information about the resources that have been spent.

The key mechanism is that dishonest individuals, i.e. those with a low level of lying aversion, have more to gain from standing for election than honest individuals, and are therefore willing to invest more to become a candidate. This is most obvious if candidates play "pooling" strategies with respect to campaign promises. In this case, both types enjoy the same probability of being elected ceteris paribus. In case of an election victory, the less honest candidate will deviate more strongly from his promise thereby reaping higher private benefits. As a consequence, the less honest potential candidate will invest more in an opaque entry contest and hence win it with a higher probability. Therefore, our analysis predicts adverse selection into politics with an opaque entry contest. ${ }^{2}$ By contrast, in the transparent entry contest, voters can observe how much each potential candidate spends in the entry contest and can make inferences about their honesty. With the dishonest individuals not wanting to separate themselves from the honest ones, we predict "pooling" in entry contest investments as well as in campaign promises. Consequently, we expect no adverse self-selection into politics with a transparent preselection process.

These theoretical predictions naturally rely on assumptions on preferences and beliefs. Other motives to self-select into politics are plausible as well. For example, candidates might derive utility from truth-telling or from fulfilling promises. ${ }^{3}$ Candidates with strong preferences for equality also have an incentive to enter politics in order to prevent unequal outcome distributions that result if a dishonest, selfish candidate wins the election. In such cases, we would expect a higher willingness to pay to enter politics of honest people - the opposite of our prediction. For these reasons, we test our theoretical predictions in a laboratory experiment featuring two treatments - one with an opaque and one with a transparent entry contest. Our results strongly support our theoretical predictions: we observe adverse selection under opaque but not under transparent entry competition.

Our analysis suggests that the preselection phase of a political race is crucial for the

\footnotetext{
${ }^{2}$ Note that this mechanism is not specific to our political economy application but can also be used to explain self-selection of dishonest people into many other cheap talk situations in which they could gain from communicating strategically. We discuss this in more detail at the end of the paper.

${ }^{3}$ The findings in Geng et al. (2011) and Corazzini et al. (2014), for example, are also rationalizable in a model with such preferences.
} 
composition of the candidate pool and election outcomes. It highlights the importance of choosing the right set of rules in order to incentivize the right people to enter politics a problem long identified by influential thinkers like Madison or Socrates who famously explained to Glaucon: "The truth is surely this: that city in which those who are going to rule are those least eager to do so is necessarily governed best [...]" (in Plato's The Republic). Transparency helps in this respect because it penalizes those who are most eager to run with a lower probability of winning the election if they actually invest more in the entry contest, and thus increases the chance of an honest candidate's win.

The rest of the paper is organized as follows. In the next section, we discuss the related literature. In Section 3, we present and solve the model. The experimental design is laid out and the experimental results are reported in Section 4. In the final Section 5, we conclude with a discussion of our findings.

\section{Related Literature}

Theoretical In the last two decades, there has been a shift away from modeling political competition exclusively as strategic position taking of purely office-motivated candidates. Various models have been proposed in which candidates compete who differ in their policy preferences or other characteristics, such as competence, public spirit, honesty, and lying aversion. Examples include the work of Callander and Wilkie (2007) who assume heterogeneous candidates with respect to two dimensions: policy preferences and lying aversion, Kartik and McAfee (2007) who allow for non-strategic candidates of character, and Buisseret and Prato (2016) who look at candidates with different skill levels.

Another string of papers has studied the incentives of people with different skills to enter politics (e.g., Messner and Polborn, 2004; Mattozzi and Merlo, 2007, 2008). Caselli and Morelli (2004) study the decision to run for office in a citizen candidate set-up in which citizens do not only differ in terms of skills but also in terms of honesty, defined as incorruptibility. Bernheim and Kartik (2014) assume heterogeneity of potential candidates with respect to public spirit (altruism) and honesty (incorruptibility). Their study is most closely related to our model. The authors study how the candidate pool changes with 
different fixed costs of entry as candidates differ with respect to their willingness to pay to become a candidate. Different from the other papers, they pay direct attention to the costs that are associated with running for nomination - an aspect that takes center stage in our model as well. However, our focus is somewhat different insofar as our focus is on honesty, not in the sense of incorruptibility as in their study, but in the sense of trustworthiness with respect to campaign promises - very salient elements of all political campaigns.

Rather than trying to pick an honest leader who adheres to her campaign promises, another strand of literature addresses the concern on how to align campaign promises and actions in office in democratic political systems by augmenting the electoral process by additional institutions that sanctions deviations from promised actions (see, e.g., Gersbach and Schneider, 2012a,b).

Empirical Our paper builds on the assumption of heterogeneity with respect to lying aversion. Geng et al. (2011) and Corazzini et al. (2014) have recently shown in lab experiments that campaign promises may not be pure cheap talk. ${ }^{4}$ In their experiments, candidates make promises to voters about how they will split a pie that the election winner receives between themselves and the voters. They find that: (i) candidates promise a lot; (ii) candidates who promise more receive more votes; (iii) higher promises are associated with higher transfers to the voters. Corazzini et al. (2014) explain their results with lying aversion of the candidates and argue that elections are good for voter welfare because they cause high electoral promises which are, at least partially, met. ${ }^{5}$ However, as our study points out, if it is true that lying aversion drives their results, it should be the case that it is much more attractive to become a candidate for people with low lying aversion who have no problem with promising much and keeping the pie for themselves. Adverse selection effects might be the consequence.

Taking are more general perspective, Sobel (2013) calls for experiments to study selfselection into cheap talk situations. Our experiment does just that in the context of our

\footnotetext{
${ }^{4}$ There are a number of recent experiments that demonstrate that many people display psychological costs of lying in other contexts as well. (see, e.g., Charness and Dufwenberg, 2006; Gneezy et al., 2013; Fischbacher and Föllmi-Heusi, 2013). Abeler et al. (2016) give an excellent overview of this literature.

${ }^{5} \mathrm{~A}$ different question that has been studied using a similar experimental framework but featuring repeated elections is whether voters vote retrospectively or prospectively (Feltovich and Giovannoni, 2015).
} 
political economy model. ${ }^{6}$

\section{Model}

We set up a simple sequential game to represent a two stage political selection process where politicians compete in an entry contest at the first stage to become a candidate in an election at the second stage. We consider four politicians of two different parties. At the first stage, there are two simultaneous entry contests in the two parties. In each of the entry contests, the two politicians of each party compete to stand for election against the winner of the other party's entry contest. Every politician $i$ makes an investment $I_{i} \in$ $[\epsilon, \infty)$, with $\epsilon>0$, in her party's contest. We assume standard properties for the contest success function: The probability of winning candidacy increases in the politician's own investment and declines with the opponent's bid. For concreteness, we use a Tullock contest success function that defines the probability of player 1 winning the contest against player 2 as

$$
\rho\left(I_{1}, I_{2}\right)=\frac{I_{1}}{I_{1}+I_{2}} .
$$

As the winning probability is not defined for $I_{1}=I_{2}=0$, we impose that investments have to be larger or equal to some small positive number $\epsilon .^{7}$

The two winners of the parties' entry contests will stand for election at the second stage of the political competition. In their election campaigns, each candidate makes a promise $P_{i}$ of how much of a budget $B$ to transfer to the $N$ voters ( $N$ odd for simplicity). Every voter finally receives the same transfer $\frac{T}{N} \in\left[0, \frac{B}{N}\right]$ from the election winner who transfers $T$ in total. ${ }^{8}$

At the election stage, the voters cast their votes for either of the candidates. A central novelty and focus of our model is on the information set that voters possess when voting.

\footnotetext{
${ }^{6}$ With a slightly different focus, Barfort et al. (2015) and Hanna and Wang (2015) study self-selection into the public service of Denmark and India, respectively, of people with different degrees of honesty.

${ }^{7}$ The alternative would be to define the winning probability as $\frac{1}{2}$ for this case. However, this would not eliminate the discontinuous jump of $\rho$ at $I_{1}=I_{2}=0$. Additionally, we emphasize that our main theoretical results do not depend on the Tullock success function.

${ }^{8}$ We only use indices for the choice variables if necessary for understanding, e.g. if we have to distinguish several players in the same role.
} 
In a transparent entry contest, the voters can observe the entry contest investments of the candidates, while in an opaque entry contest the voters will have no information on the candidates' entry investments.

When in office, the winner of the election will finally decide how to split the budget of size $B$ between her own private benefit $B-T$ and the voters' welfare $T .{ }^{9}$ Besides the remaining budget $B-T$, the elected politician obtains a rent from office $W$ that is not transferable. $W$ can be thought of as a salary, or an ego rent, or both.

Politicians have preferences over private consumption and, given they are elected into office, the discrepancy between their campaign promises and the actual contribution to voter welfare, i.e., $P-T$. We refer to the latter as the politician's lying aversion or character. For the politicians' utility functions, we use a quasi-linear specification ${ }^{10}$

$$
U_{i}\left(I_{i}, P_{i}, T_{i}\right)=-I_{i}+1_{\mathrm{i}, \text { office }}\left(W+B-T_{i}-\frac{\beta_{i}}{2} \frac{\left(\max \left\{P_{i}-T_{i}, 0\right\}\right)^{2}}{P_{i}}\right) .
$$

The parameter $\beta_{i}$ reflects the politician's weight attached to promise keeping. $\beta_{i}$ can take two values, $\beta_{L}$ and $\beta_{H}$, with $\beta_{H}>\beta_{L}$. The higher the value of $\beta_{i}$ is, the higher are the utility costs incurred by deviating from the campaign promise. We assume that politicians have either low, $\beta_{L}$, or high lying aversion, $\beta_{H}$, with $\beta_{L} \geq 0$ and $\beta_{H}>1$. This means that the high type will, at least partially, fulfill her election promise in case of an election win, whereas the low type will keep the whole budget for herself if $\beta_{L} \leq 1$ and only make transfers if $\beta_{L}>1$. The ex ante probability of a politician to be of type $H$ is $\phi$. This probability and all other parameters are common knowledge, whereas the realized $\beta_{i} \mathrm{~s}$ are private information. The indicator function $1_{\mathrm{i} \text {, office }}$ indicates that the latter part of utility will only be realized when the politician $i$ wins office. The voters only care about the amount $\frac{T}{N}$ in consumption that they receive. ${ }^{11}$

\footnotetext{
${ }^{9}$ This is a shorthand for various moral hazard problems that are present when voters delegate power to a politician. The politician might not literally put government money into her own pocket but still enrich herself by employing resources that come with the office for her own rather than the voters' benefit or simply exert less effort in working in the voters' interest than promised.

${ }^{10}$ This allows us to illustrate the key mechanisms in a simple way and provides comparability to the previous literature, e.g. Corazzini et al. (2014). We note that our key results do not depend on this specification of the lying costs. Sufficiently high fixed costs of lying, for example, would work as well.

${ }^{11}$ Note that one could reasonably argue that voters do not only care about money either and suffer a (nonmonetary) utility loss from a liar winning the election. This disutility would come in addition to the lower
} 
We can now summarize the structure of the political game as follows.

Stage 0: [Type Assignment] Nature draws the four individuals' types independently. Each individual will be of high (lying aversion) type with probability $\phi$ and of low (lying aversion) type with probability $1-\phi$. The individuals' types are private knowledge.

Stage 1: [Entry contests] The two politicians in each of the two parties invest amount $I_{i}$ in the parties' entry contests.

The winner is determined via a (Tullock) contest success function.

Stage 2: [Election campaign] The two winners of the entry contest become the candidates in the election and promise an amount $P_{i}$ to pass on to the voters when in office.

Stage 3: [Voting] The voters cast their votes, (not) observing the candidates' entry contest investments if the entry contest is transparent (opaque).

Stage 4: [Policy implementation] The winner in the election obtains fixed wage $W$ and decides on the transfer $T$ to the voters out of a budget of size $B$.

The central innovation of our paper is Stage 1 of the game, in which the entry contest is either transparent to the voters or opaque. The distinction between these two institutional settings is best indicated in the game description at stage three where the voters cast their votes based on different information sets. The voters vote for the candidate that they expect to deliver the higher transfer, i.e. they vote for candidate $i$ if her expected transfer

$$
E\left[T_{i}\right]=\tilde{\phi}_{i} T_{H}+\left(1-\tilde{\phi}_{i}\right) T_{L}
$$

utility they derive from the lower transfer they would receive from such a politician as compared to the transfer they would have received from an honest politician winning the election ceteris paribus. However, this additional effect would not change the vote choice and we therefore chose to keep the voters' utility function simple. 
is higher than that of her opponent's. ${ }^{12}$ The voters' beliefs of candidate $i$ being of high type is denoted by $\tilde{\phi}_{i}$. In the regime with the transparent entry contest, the voters' beliefs $\tilde{\phi}$ are a function of the candidates' promises $P$ as well as the entry contest investments $I$. By contrast, the beliefs cannot be influenced by the entry contest investments in the opaque entry contest.

The politicians know of the effects of their investments and promises on the voters' beliefs and maximize expected utility

$$
E\left[U_{i}\right]=-I_{i}+p_{\mathrm{i}, \text { contest }} * p_{\mathrm{i}, \text { office }} *\left\{W+B-T_{i}-\frac{\beta_{i}}{2} \frac{\left(\max \left\{P_{i}-T_{i}, 0\right\}\right)^{2}}{P_{i}}\right\}
$$

by choosing the triple $\left(I_{i}, P_{i}, T_{i}\right) \cdot p_{\mathrm{i}, \text { contest }}$ and $p_{\mathrm{i}, \text { office }}$ reflect the probabilities of winning the entry contest and winning office in the general election. The probability for winning office $p_{\mathrm{i}, \text { office }}$ of course depends on the voters' beliefs.

The solution concept we use is Symmetric Perfect Bayesian Equilibrium in pure strategies. By "symmetric" we refer to equilibria where politicians of the same type employ the same strategy. In either entry regime there can be both pooling and separating equilibria. We characterize all equilibria in the Appendix. Here, we focus on the key properties of the equilibria with respect to self-selection, starting with the opaque entry contest regime.

Proposition 1. [Opaque Entry]

Consider the political game with opaque entry contest.

- In all but one Symmetric Perfect Bayesian Equilibria, politicians with a low level of lying aversion (low types) invest strictly more in the entry contest than politicians with a high level of lying aversion (high types).

- The only exception is a knife-edge case in which both types pool on promising zero transfers in the campaign stage and $\beta_{L} \leq 1$, which is not robust to small perturbations of out-of-equilibrium beliefs.

Proof. See Appendix

\footnotetext{
${ }^{12}$ If a voter expects the same transfer from either of the two candidates, we assume that she flips a coin and votes for either of them with probability one half.
} 
It is easy to see that low types are better off in equilibria in which both types pool in the campaign stage and promise the same transfer. Such equilibria exist for all admissible parameter values. The logic behind these equilibria is that voters prefer a high type in office as the high type would make a higher transfer, given the same campaign promises, except for the special case of pooling on promises of zero transfers. Hence, the low type does not wish to reveal himself and pools with the high type. As entry contest investments cannot be observed by voters, the candidates make the same campaign promises but different types make different entry contest investments. The low type will invest more than the high type as her expected value from winning the entry contest is higher than that of the high type.

For some parameter settings, also separating equilibria exist in which the high type makes a substantially lower promise in the election campaign such that the expected transfer for the voters will be higher from a low lying aversion type. In this case, the voters prefer to vote a low type into office rather than a high type and the high type candidate only has a chance to be elected when competing against another high type in the general election. The high type does not want to increase her election chances by mimicking the low type as the lower promise will increase the payoff in the event of winning office sufficiently (due to the lower lying costs) to compensate for the loss in winning probability. For the low lying aversion type, the loss of making high promises and only partially honoring them is not as large in terms of utility, so that the low type is willing to accept a lower benefit in the event of winning office in exchange for a higher winning probability, relative to mimicking the high type. In the Appendix, we show that also in these equilibria low types are always better off than high types and are therefore willing to invest more to become a candidate.

From Proposition 1 we derive our first hypothesis which summarizes the direct consequences of the predicted higher investments of low types.

H1: In the political game with opaque entry contest, there will be a negative correlation between entry contest investment I and transfer $T$ and a positive correlation between entry contest investment I and the politician's lie size $P-T$. As a consequence, we will 
observe an adverse effect on voter welfare (in terms of transfers).

In the transparent entry contest regime, there can again be separating and pooling equilibria. Importantly, the pooling equilibria include pooling at the entry stage and, hence, no adverse selection.

Proposition 2. [Transparent Entry]

Consider the political game with transparent entry contest.

(a) For all admissible parameter values, there are Symmetric Perfect Bayesian Equilibria in which both types of politicians pool and invest the same amount in the entry contest.

(b) There are also Symmetric Perfect Bayesian Equilibria in which low types invest strictly more in the entry contest than high types. However, these separating equilibria do not exist for all admissible parameter values.

Proof. See Appendix

There are separating equilibria with the exact same structure as those under the opaque entry regime and further separating equilibria that we characterize in the proof in the Appendix. However, these equilibria do not always exist and appear less intuitive than pooling equilibria. Therefore, we adopt the working hypothesis that a pooling equilibrium will be played. In these equilibria, the low type will pretend to be of high type in the entry contest as well. This has the direct consequence that the transparent entry contest will not lead to adverse selection.

H2: In the political game with transparent entry contest, there will be no correlation between entry contest investment I and transfer T or the politician's lie size P - T. As a consequence, adverse effects on voter welfare will be effectively reduced as compared to the opaque entry regime.

Both hypotheses are testable and it is not clear ex ante that they will predict behavior accurately. Maybe subjects play a separating equilibrium in the transparent entry treat- 
ment. Furthermore, subjects might not display psychological costs of lying as assumed in our model, or instead derive utility from being nice to voters and fulfilling promises. All of these factors could lead to quite different behavior than we hypothesize. Ultimately, these are empirical questions and it is therefore a natural next step to run an experiment.

\section{Experiment}

To test the main predictions of the model, we ran a laboratory experiment with two treatments - one with an opaque and one with a transparent entry stage. Costs of lying are not induced and therefore can only result from the subjects' psychology. A potential confounding factor that could also lead to adverse selection are income effects. Subjects who invest more in the entry contest might be less honest or benevolent, not because of their lying aversion, but because they are poorer and potentially further away from their target income from participating in the experiment. To address this issue, we slightly depart from the model and have subjects pay their entry contest investment only with probability one half. All subjects in a certain round of the same session are in the same condition as this randomization occurs at the round level. They are informed about the fact whether they have to pay their investment or not right after the contest and before the campaign and election stages. Therefore, findings in the sub-sample of subjects who do not have to pay their investment cannot be confounded by income effects. This change of the set-up does not change any of the qualitative results in Propositions 1 and 2 as compared to the set-up presented in the previous section. ${ }^{13}$ The only difference is that the equilibrium investments are predicted to be twice as high for all types of potential candidates.

\footnotetext{
${ }^{13} \mathrm{~A}$ technical discussion of this aspect is provided in Appendix A2.
} 


\subsection{Experimental Design}

We ran one pre-test and five sessions of either treatment. ${ }^{14}$ Each session consisted of 20 rounds. In the first round, subjects were randomly assigned a role: $\frac{3}{7}$ were assigned the role "voter" and $\frac{4}{7}$ the role "politician". Roles were fixed for the whole experiment. In every round, groups with three voters and four politicians were randomly formed. Politicians were randomly divided into parties A and B with two politicians each. We set $B=270$, $W=50$ and let politicians start every round with 100 points, out of which the entry contest investment is paid, and voters with a budget of 50 points in order to roughly equalize expected pay-offs for voters and politicians in the experiment. At the end, one round was randomly selected and subjects paid according to their income from that round plus a show-up fee of EUR 2. One point was worth EUR 0.2 and average earnings were EUR 22 for approximately 100 minutes in the lab.

Decision Stages On the first screen of the first round, subjects were informed about their role. Subjects then faced the following decision stages which mirror the stages of the model as presented in Section 3. The two treatments only differ in Stage 3.

Stage 1: $\quad$ Politicians had to enter their investment for the entry competition of [Entry] their party on the first screen of every round. On the following screen, they had to enter their (non-incentivized) belief regarding the probability of winning the contest.

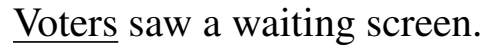

\footnotetext{
${ }^{14}$ We had four sessions with 28 subjects and two with 21 subjects for either treatment. They were recruited using ORSEE (Greiner, 2015). Participants in the pre-test are experienced subjects. Psychology and Political Science students were not recruited. All sessions were run at the LakeLab at the University of Konstanz in 2015 and 2016. Instructions can be found in the Appendix. The experiment was programmed in z-Tree (Fischbacher, 2007).
} 
Stage 2: $\quad$ Politicians were informed about whether the entry contest investment [Campaign] had to be paid or not. Then they had to enter their election promise $P_{i}$ under the assumption that they won the entry contest. On the following screen, they had to enter their (non-incentivized) belief regarding the probability of winning the election.

Voters had to wait until politicians had entered their election promise and saw a waiting screen.

\section{Opacity}

Stage 3O: $\quad$ Politicians went on to Stage 4 straight away.

[Voting]

Voters were informed about the election promises of the two candidates in the election, i.e. the two candidates that won their entry contests, and whether or not they had to pay their investments, and had to cast their vote for one of the candidates. On the following screen, they had to enter their (non-incentivized) belief regarding the transfer from each of the two candidates.

$\underline{\text { Transparency }}$

Stage 3T: $\quad$ Politicians went on to Stage 4 straight away.

[Voting]

Voters were informed about the election promises and entry stage investments of the two candidates in the election, and whether or not they had to pay their investments, and had to cast their vote for one of the candidates. On the following screen, they had to enter their (non-incentivized) belief regarding the transfer from each of the two candidates. 
Stage 4: $\quad$ Politicians had to enter their transfer $T_{i}$ to the voters under the assump[Policy] tion that they had won the election. We use the 'strategy method' here and in Stage 2 to collect data on the (ultimately not realized) promises and transfers of entry contest and election losers, respectively.

Voters faced a waiting screen if they had completed Stage 3 before the politicians finished Stage 4.

On a final feedback screen, politicians and voters were informed about their payoffs and their group members' decisions. They were only informed about decisions that were realized, i.e. they neither received feedback about promises of entry contest losers nor feedback about the transfer decisions of entry contest and election losers.

\subsection{Experimental Results}

First, we present and discuss the results in the opaque entry treatment and will then contrast them with those in the transparent entry treatment.

All sessions including the pretests are used to compute the following results. ${ }^{15}$ Standard errors are computed with clustering at the session level. As the number of clusters is equal to the number of sessions and therefore low, we also run non-parametric tests treating each session as a single observation. The labels paid, not paid, and all indicate whether estimates are for the rounds in which the entry contest investment had to be paid, or not, or all rounds, respectively.

\subsubsection{Opaque Entry Treatment}

We start with the election stage and then turn to the entry stage. Following a backward induction logic, this is more intuitive as behavior in the first stage is better understood when already knowing second stage behavior.

\footnotetext{
${ }^{15} \mathrm{All}$ results also hold with the restricted sample without the pre-tests.
} 
Campaign/Election Stage We start by studying the effect of promises on the probability of winning the election, conditional on winning the entry contest. Table 1 shows that higher promises increase the chances of winning. Adding the promise squared to check for non-linearities does not change results. The squared term is never significant and therefore omitted here. $61 \%$ of all election winners had promised more than their opponents (excluding pairs with identical promises).

Table 1: Opaque Entry: Chance of Winning and Promise

\begin{tabular}{lcccccc}
\hline \hline & \multicolumn{2}{c}{ all } & \multicolumn{2}{c}{ paid } & \multicolumn{2}{c}{ not paid } \\
\hline Promise & $0.217^{* * *}$ & $(0.021)$ & $0.143^{* *}$ & $(0.055)$ & $0.291^{* * *}$ & $(0.020)$ \\
_cons & -0.789 & $(4.973)$ & 16.820 & $(12.897)$ & $-18.460 * *$ & $(5.048)$ \\
\hline$N$ & 880 & & 394 & & 486 & \\
$R^{2}$ & 0.03 & 0.01 & 0.05 & \\
N_clust & 6 & 6 & 6 & \\
\hline \hline
\end{tabular}

Note: Linear Probability (in percentage points) Models with the dummy winner [0;100] as the dependent variable. Standard errors in parentheses are adjusted for clustering at the session level. Levels of significance: ${ }^{*} \mathrm{p}<0.10, * * \mathrm{p}<0.05, * * * \mathrm{p}<0.01$.

The election chances increase as promises positively influence the voters' beliefs about the size of the transfer. Regressing the difference in expectations regarding the transfer from the two candidates on the difference in their promises shows a positive relationship (Table A1, Appendix). Anticipating the voters' reaction, the candidates make high promises (Figure 1). Figure 2 shows the empirical cumulative distribution function of the transfers made by all potential candidates. Roughly one third of the potential candidates give nothing or almost nothing. A few politicians fully meet their promise, the vast majority partially fulfills their promises and distribute a part of it.

Voter beliefs are rational: higher promises are positively correlated with higher transfers (Table A2, Appendix). The correlation is stronger if the entry contest investments do not have to be paid, suggesting that income effects indeed play a role. We can summarize our findings as follows. 
Figure 1: Cumulative Density Plots of Promises

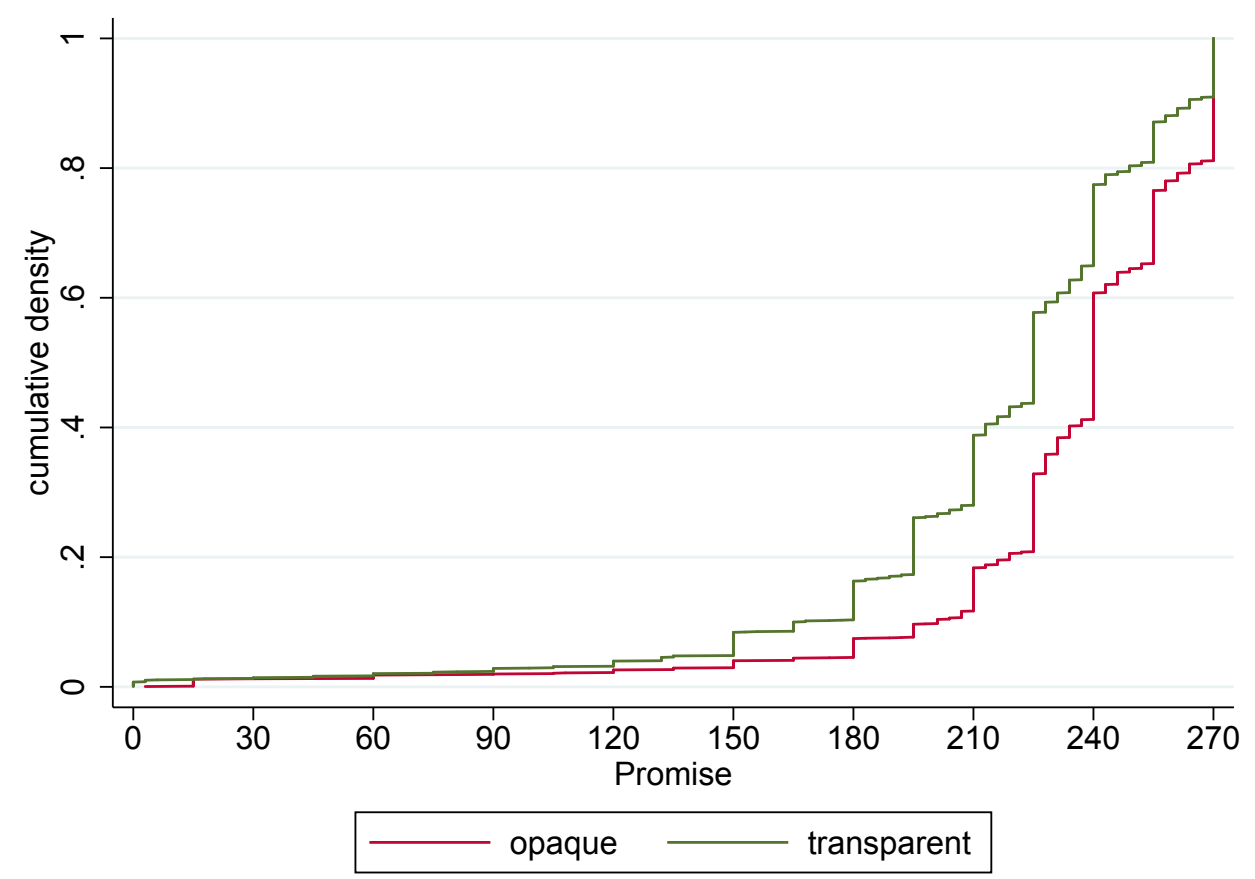

Note: These are the promises of all subjects in the role of politicians, including those who lost the entry stage contest.

Result $1 \quad$ Candidates promise very high transfers.

- Higher promises increase their chance of winning the election.

- Promises are positively correlated with the transfers. However, a substantial number of candidates choose to make no transfers.

Entry Stage (opaque) The entry contest investments in the opaque treatment are on average 46.5 points but show substantial variance (Figure 3). As shown in Appendix A2, the optimal entry contest investments depend considerably on the contestants' degrees of lying aversion. As discussed there, within our model framework, we can accommodate 
Figure 2: Cumulative Density Plots of Transfers

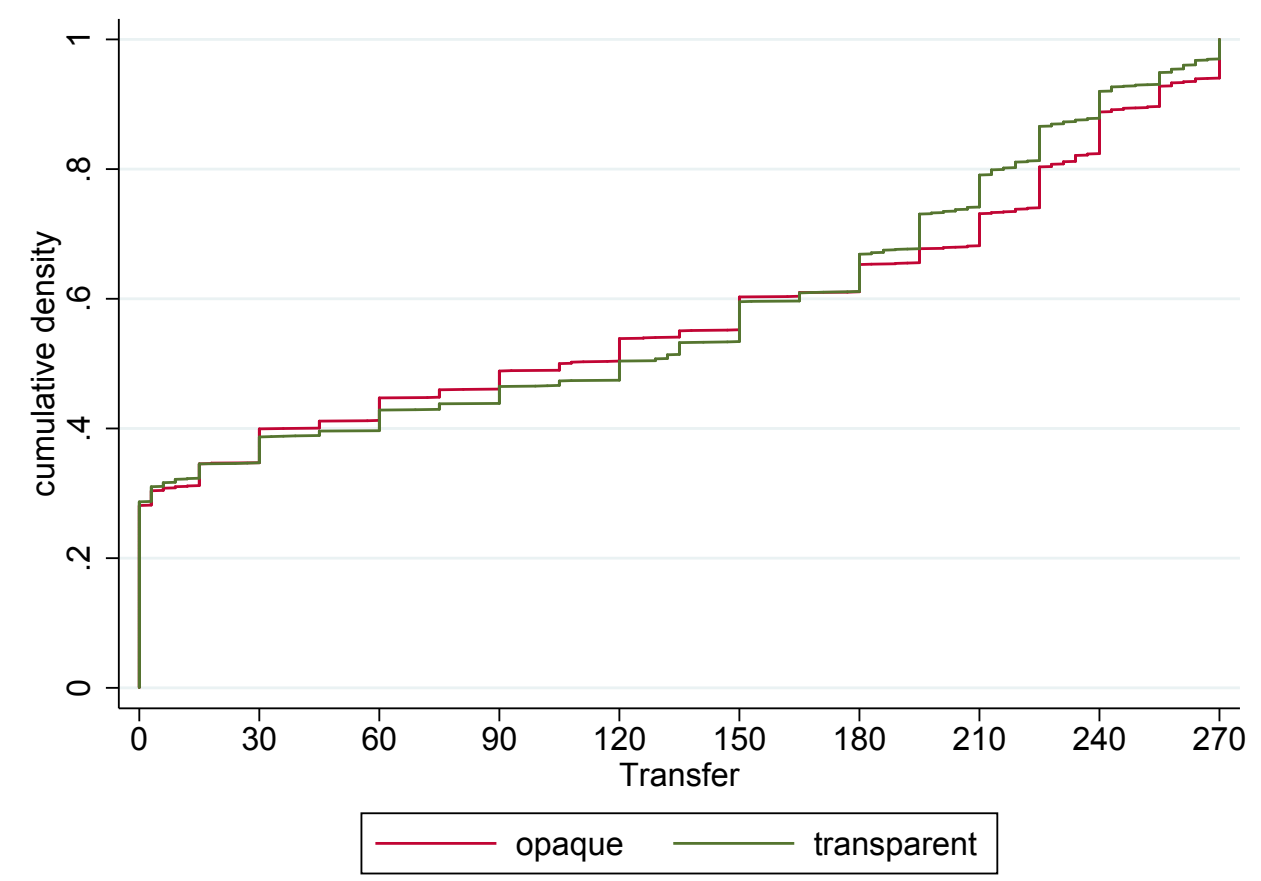

Note: These are the transfers of all subjects in the role of politicians, including those who lost the entry stage contest or the election.

entry bids up to 80 points for individuals without any lying aversion at all, and as low as 9 points for entirely honest individuals. As Figure 3 illustrates, the vast majority of entry contest investments fall within this range.

Next, we ask whether subjects who invest more also lie more. The first three columns in Table 2 present the estimates of regressions of the lie size (promise minus points distributed) on the entry contest investment. The coefficient is significantly different from zero and positive, confirming our prediction that higher investments will be associated with larger lies. This is also the case for the situations in which the entry contest investment does not have to be paid. Running this regression separately for all six sessions results in positive coefficients for the investment in all six of them (for all, paid, and not 
Figure 3: Cumulative Density Plots of Entry Contest Investments

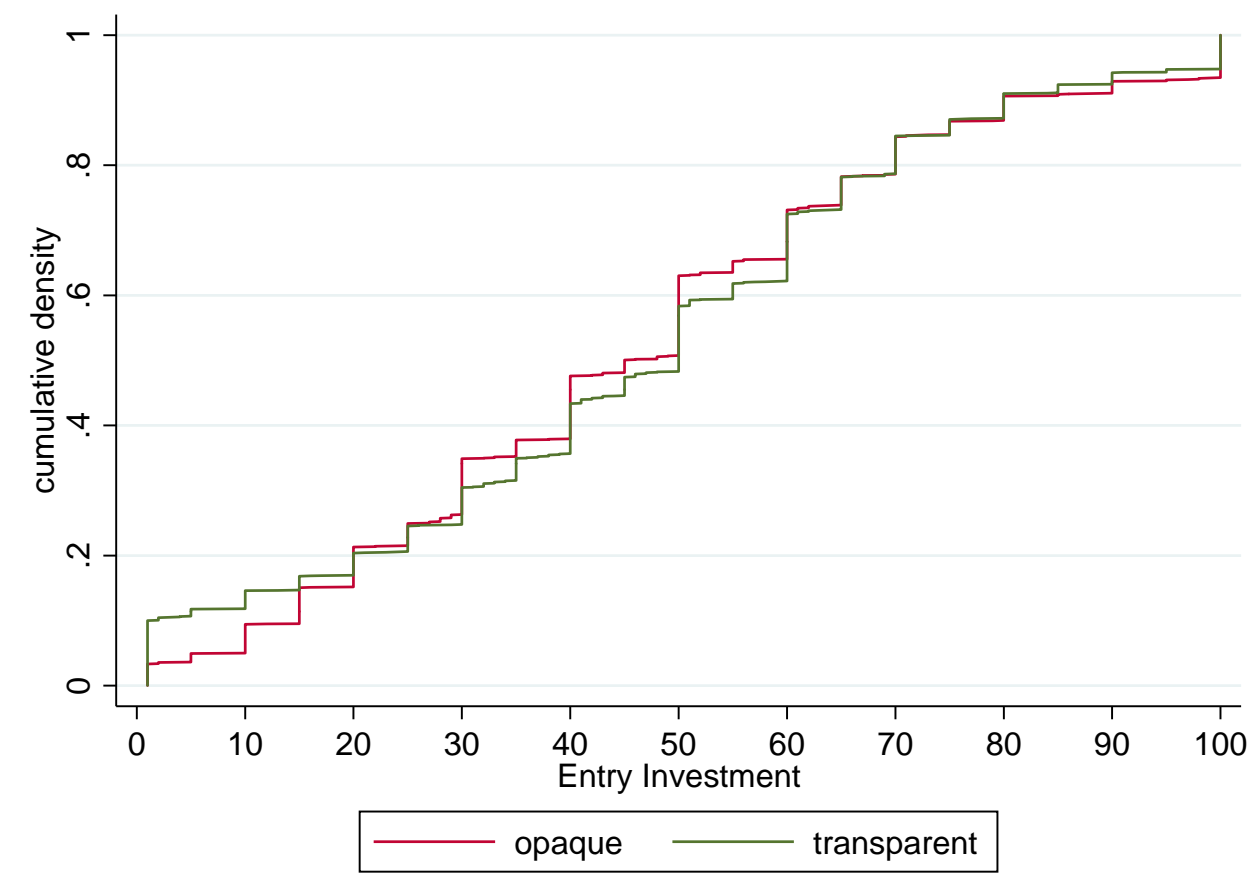

Note: These are the entry stage investments of all subjects in the role of politicians.

paid). A simple binomial test treating the six separately estimated coefficients as independent observations thus rejects the Null that there is no effect at the $5 \%$ level.

The question is now whether points distributed are correlated with the entry contest investments. The last three columns of Table 2 present the estimates of regressions of points distributed on the entry contest investment. The effect is strongly significant and negative. This is also the case for the situations in which the entry contest investment did not have to be paid. Running this regression separately for all six sessions results in negative coefficients for investment in all six of them (for all, paid, and not paid), providing also non-parametric support, in form of a Binomial test as sketched above, for our theoretical prediction.

The remaining question is how large the adverse selection effect is. In a Tullock contest 
Table 2: Opaque Entry: Investments, Lie Size, and Transfer

\begin{tabular}{lccc|ccc}
\hline \hline & $(\mathrm{P}-\mathrm{T})$, all & $(\mathrm{P}-\mathrm{T})$, paid & $(\mathrm{P}-\mathrm{T})$, not paid & $\mathrm{T}$, all & $\mathrm{T}$, paid & $\mathrm{T}$, not paid \\
\hline Investment & $0.753^{* * *}$ & $0.725^{* *}$ & $0.770^{* * *}$ & $-0.625^{* * *}$ & $-0.615^{* * *}$ & $-0.625^{* * *}$ \\
& $(0.149)$ & $(0.195)$ & $(0.133)$ & $(0.102)$ & $(0.128)$ & $(0.113)$ \\
\multirow{2}{*}{ cons } & $84.054^{* * *}$ & $90.115^{* * *}$ & $79.496^{* * *}$ & $143.479^{* * *}$ & $136.739 * * *$ & $148.606 * * *$ \\
& $(11.565)$ & $(13.849)$ & $(10.958)$ & $(9.995)$ & $(10.759)$ & $(10.994)$ \\
\hline$N$ & 1760 & 788 & 972 & 1760 & 788 & 972 \\
$R^{2}$ & 0.03 & 0.03 & 0.04 & 0.03 & 0.02 & 0.03 \\
N_clust & 6 & 6 & 6 & 6 & 6 & 6 \\
\hline \hline
\end{tabular}

Note: OLS models with lie size (P-S) or Transfer T as dependent variables. Standard errors in parentheses are adjusted for clustering at the session level. Levels of significance: $* \mathrm{p}<0.10, * * \mathrm{p}<0.05, * * * \mathrm{p}<0.01$.

the lower investment often wins if both investments are relatively close. This introduces a lot of noise into the data which is not related to subjects' behavior. Instead of comparing behavior of winners and losers of the entry contest, we compute the expected values of points distributed of losers and winners given their winning probabilities which are pinned down by their investment and their opponent's investment in the contest. For each pair of potential candidates 1 and 2 we compute:

$$
\begin{aligned}
E(T \mid \text { winner }) & =T_{1} \times \frac{I_{1}}{I_{1}+I_{2}}+T_{2} \times \frac{I_{2}}{I_{1}+I_{2}} \\
E(T \mid \text { loser }) & =T_{1} \times\left(1-\frac{I_{1}}{I_{1}+I_{2}}\right)+T_{2} \times\left(1-\frac{I_{2}}{I_{1}+I_{2}}\right) .
\end{aligned}
$$

The difference $E(T \mid$ winner $)-E(T \mid$ loser $)$ is our measure of the adverse selection effect. The effect amounts to -10.43 , which is $9 \%$ of the average transfer. It is -10.01 if the entry contest investment has to be paid and -10.77 if it does not have to be paid. The effect is significantly different from zero at the $1 \%$ level and negative in all six sessions. This establishes the following key result. 
Result 2 Confirming H1, dishonest politicians over-proportionally self-select into the political race, leading to lower expected transfers to the voters than those they would have received from entry contest losers.

\subsubsection{Transparent Entry Treatment}

We now turn to the transparent entry treatment and a comparison with the findings in the opaque entry treatment.

Campaign/Election Stage In this treatment, voters learn about both candidates' entry contest investment in addition to their election promise. Table 3 shows that higher investments are associated with a lower probability of winning the election. This effect is stronger if the entry contest investment has to be paid. Again the reason for the positive effect of higher promises and the negative effect of higher investments can be found in the voters' beliefs (Table A3, Appendix). Higher promises are believed to entail higher transfers while higher entry contest investments are expected to indicate lower transfers. These beliefs are again supported by the correlations between actual transfers and promises, and between promises and entry contest investments (Table A4, Appendix).

Table 3: Transparent Entry: Chance of Winning, Investment and Promise

\begin{tabular}{lcccccc}
\hline \hline & \multicolumn{2}{c}{ all } & \multicolumn{2}{c}{ paid } & \multicolumn{2}{c}{ not paid } \\
\hline Investment & $-0.255^{* * *}$ & $(0.058)$ & $-0.433^{* *}$ & $(0.167)$ & -0.134 & $(0.088)$ \\
Promise & $0.199 * * *$ & $(0.045)$ & $0.233^{* * *}$ & $(0.055)$ & $0.178 * *$ & $(0.056)$ \\
_cons & 20.927 & $(12.151)$ & 25.225 & $(14.563)$ & 17.553 & $(15.908)$ \\
\hline$N$ & 880 & & 422 & & 458 & \\
$R^{2}$ & 0.03 & & 0.06 & & 0.02 & \\
N_clust & 6 & & 6 & & 6 & \\
\hline \hline
\end{tabular}

Note: Linear Probability (in percentage points) Models with the dummy winner [0;100] as the dependent variable. Standard errors in parentheses are adjusted for clustering at the session level. Levels of significance: $* \mathrm{p}<0.10, * * \mathrm{p}<0.05, * * * \mathrm{p}<0.01$. 
Result 3 Voters react to the additional information on investments in the entry contest. Higher entry contest investments lower the chance of winning the election.

The distributions of promises, points distributed to the voters, and entry contest investments of all potential candidates (Figures 1-3) look similar to those under opaque entry competition. ${ }^{16}$ However, as our theoretical predictions suggest, the relations between them are profoundly different as we discuss next.

Entry Stage (transparent) The first question is whether the association between the size of the lie and the entry contest investment is smaller than in the opaque entry treatment. Indeed, the coefficients in the first three columns in Table 4 are all smaller than those in Table 2 (the analog table for the opaque treatment). We find the same result when we look at transfers instead of lie size: the significantly negative relationship between entry contest investments and transfers in the opaque treatment vanishes in the transparent treatment. The signs of the coefficients in the opaque and transparent treatment go in the same directions. While the coefficients on the effect of entry contest investments on the lie size is not statistically different between the opaque entry and transparent entry treatments according to either parametric or non-parametric (rank-sum) tests, the ones representing the effect between entry contest investments and transfers are (at the 5\% level). ${ }^{17}$

As we can expect from these results, the substantial adverse selection effect in terms of expected transfers in the opaque entry treatment disappears in the transparent treatment. Computing adverse selection effects using equation (4) results in an average effect of -0.59 , which is statistically not different from zero but significantly different from the effect under opaque entry competition at the 5\% level, both with parametric or nonparametric (rank-sum) tests. This establishes our final key result.

\footnotetext{
${ }^{16}$ Only promises are significantly different (lower with transparent entry contest investments), on average, at the $10 \%$ level ( $t$-tests).

${ }^{17}$ For the rank-sum test we again estimate each coefficient separately for each session. These 12 estimates ( 6 for each treatment) are the independent observations used to compute the test statistic.
} 
Table 4: Transparent Entry: Investments, Lie Size, and Transfer

\begin{tabular}{lccc|ccc}
\hline \hline & $(\mathrm{P}-\mathrm{T})$, all & $(\mathrm{P}-\mathrm{T})$, paid & $(\mathrm{P}-\mathrm{T})$, not paid & $\mathrm{T}$, all & T, paid & T, not paid \\
\hline Investment & 0.469 & $0.528^{*}$ & 0.438 & -0.249 & -0.289 & -0.209 \\
& $(0.260)$ & $(0.248)$ & $(0.288)$ & $(0.245)$ & $(0.278)$ & $(0.236)$ \\
\multirow{2}{*}{ cons } & $81.450^{* * *}$ & $74.723 * * *$ & $86.479 * * *$ & $124.617 * * *$ & $124.081 * * *$ & $125.077 * * *$ \\
& $(13.118)$ & $(14.098)$ & $(13.873)$ & $(14.210)$ & $(17.068)$ & $(12.920)$ \\
\hline$N$ & 1760 & 844 & 916 & 1760 & 844 & 916 \\
$R^{2}$ & 0.02 & 0.02 & 0.01 & 0.00 & 0.01 & 0.00 \\
N_clust & 6 & 6 & 6 & 6 & 6 & 6 \\
\hline \hline
\end{tabular}

Note: OLS models with lie size (P-S) or Transfer T as dependent variables.Standard errors in parentheses are adjusted for clustering at the session level. Levels of significance: $* \mathrm{p}<0.10, * * \mathrm{p}<0.05, * * * \mathrm{p}<0.01$.

Result 4 Confirming H2, transparency effectively reduces adverse selection into candidacy.

\section{Discussion and Conclusion}

Our analysis suggests that self-selection into politics plays a vital role for voter welfare. Our results highlight (a) that differences in honesty of individuals make it more or less attractive to enter the political race, and (b) that this difference in the attractiveness of running for office can lead to an unfavorable composition of the candidate pool and consequently to a bad selection of politicians.

How can democratic institutions safeguard against such adverse selection into political office? Our study argues that increasing transparency with respect to the politicians' investments in order to win the nomination could help. Profound and unbiased media coverage of all contestants appears to be crucial.

The adverse selection into politics and the associated welfare losses can also be curbed by limiting the opportunities for diverting resources in office for private gains. Next to institutional checks and balances, such limits can also come in the form of repeated game incentives, e.g. via re-election possibilities. However, the latter might not discipline dis- 
honest politicians in their last term in office.

In our model, the higher motivation of entering office of the less honest politicians originates in their higher ability to divert resources to their private benefit. Certainly, some individuals are likely to be motivated by social preferences towards the electorate as well. A number of studies, for example, show that a substantial number of people is willing to give up monetary rewards in order to generate a public good and consequently self-select into treatments where they can do so (e.g., Brekke et al., 2011; Fehrler and Kosfeld, 2014). As we do not impose preferences in our experiment, individuals with higher levels of altruism could have invested more in the entry competition to be able to do good to the voters by honouring their campaign promises and distributing all or a large part of the budget. If this was the dominant motivation to enter office, the selection effect should be opposite to our theoretical predictions. As our predictions have been confirmed in the experiment, we argue that the mechanism we emphasize appears to be dominant. While underlining the importance of our mechanism, we acknowledge that in real world settings other motives for sorting into politics that are outside our framework may play a role as well, thereby possibly attenuating the adverse selection effects that we have found.

Our results can also be interpreted in a broader context. The question who self-selects into cheap talk situations, offering gains from lying, is of general interest. Sobel (2013) for example approaches this question by asking who wants to become a salesperson. Figure A1 reports results from a Gallup survey which show that together with Members of Congress and lobbyists, members of the following three professions rank in the lowest five with respect to perceived honesty and ethical standards: advertising people, car salespeople and telemarketers. This suggests that people believe dishonest people sort into professions in which strategic communication is a core activity. Finding substantial selfselection effects in the lab, our results provide some evidence towards this view. It would be an intriguing next step for future research to examine such effects for different professions in field studies. 


\section{References}

Abeler, J., Nosenzo, D., and Raymond, C. (2016). Preferences for Truth-Telling. Mimeo.

Alesina, A. (1988). Credibility and policy convergence in a two-party system with rational voters. The American Economic Review, 78(4):796-805.

Barfort, S., Harmon, N., Hjorth, F., and Olsen, A. L. (2015). Dishonesty and Selection into Public Service in Denmark : Who Runs the World's Least Corrupt Public Sector? Working Paper.

Bernheim, B. D. and Kartik, N. (2014). Candidates, Character, and Corruption. American Economic Journal: Microeconomics, 6(2):205-246.

Brekke, K. A., Hauge, K. E., Lind, J. T., and Nyborg, K. (2011). Playing with the good guys. A public good game with endogenous group formation. Journal of Public Economics, 95(9-10):1111-1118.

Buisseret, P. and Prato, C. (2016). Electoral Control and the Human Capital of Politicians. Games and Economic Behavior, 98:1-35.

Callander, S. and Wilkie, S. (2007). Lies, damned lies, and political campaigns. Games and Economic Behavior, 60(2):262-286.

Caselli, F. and Morelli, M. (2004). Bad politicians. Journal of Public Economics, 88:759782.

Charness, G. and Dufwenberg, M. (2006). Promises and partnership. Econometrica, 74(6):1579-1601.

Corazzini, L., Kube, S., Maréchal, M. A., and Nicolò, A. (2014). Elections and Deceptions: An Experimental Study on the Behavioral Effects of Democracy. American Journal of Political Science, 58(3):579-592.

Fehrler, S. and Kosfeld, M. (2014). Pro-social missions and worker motivation: An experimental study. Journal of Economic Behavior and Organization, 100:99-110. 
Feltovich, N. and Giovannoni, F. (2015). Selection vs . accountability : An experimental investigation of campaign promises in a moral-hazard environment. Journal of Public Economics, 126:39-51.

Fischbacher, U. (2007). Z-Tree: Zurich toolbox for ready-made economic experiments. Experimental Economics, 10(2):171-178.

Fischbacher, U. and Föllmi-Heusi, F. (2013). Lies in Disguise-an Experimental Study on Cheating. Journal of the European Economic Association, 11(3):525-547.

Geng, H., Weiss, A. R., and Wolff, I. (2011). The Limited Power of Voting to Limit Power. Journal of Public Economic Theory, 13(5):695-719.

Gersbach, H. and Schneider, M. T. (2012a). Tax contracts and elections. European Economic Review, 56(7):1461-1479.

Gersbach, H. and Schneider, M. T. (2012b). Tax contracts, party bargaining, and government formation. Mathematical Social Sciences, 64(2):173-192.

Gneezy, U., Rockenbach, B., and Serra-Garcia, M. (2013). Measuring lying aversion. Journal of Economic Behavior \& Organization, 93:293-300.

Greiner, B. (2015). Subject pool recruitment procedures: organizing experiments with ORSEE. Journal of the Economic Science Association, 1(1):114-125.

Hanna, R. and Wang, S.-Y. (2015). Dishonesty and selection into public service. NBER Working Paper.

Kartik, N. and McAfee, R. P. (2007). Signaling character in electoral competition. American Economic Review, 97(3):852-70.

Mattozzi, A. and Merlo, A. (2007). The Transparency of Politics and the Quality of Politicians. American Economic Review, 97(2):311-315.

Mattozzi, A. and Merlo, A. (2008). Political careers or career politicians? Journal of Public Economics, 92:597-608. 
Messner, M. and Polborn, M. K. (2004). Paying politicians. Journal of Public Economics, 88(12):2423-2445.

Mondak, J. J. and Huckfeldt, R. (2006). The accessibility and utility of candidate character in electoral decision making. Electoral Studies, 25(1):20-34.

Sobel, J. (2013). Ten possible experiments on communication and deception. Journal of Economic Behavior \& Organization, 93:408-413. 


\section{Appendix}

\section{A1. Proofs}

Proposition 1. [Opaque Entry]

Consider the political game with opaque entry contest.

- In all but one Symmetric Perfect Bayesian Equilibria, politicians with a low level of lying aversion (low types) invest strictly more in the entry contest than politicians with a high level of lying aversion (high types).

- The only exception is a knife-edge case in which both types pool on promising zero transfers in the campaign stage and $\beta_{L} \leq 1$, which is not robust to small perturbations of out-of-equilibrium beliefs.

Proof. There can be equilibria in which types pool and promise the same transfer in the campaign stage, and separating equilibria in which low types promise a higher transfer in the campaign stage. In the first step, we characterize these equilibria and derive the result that the expected value of winning the entry contest is higher for low types. In the second step, we show that a higher expected value translates into a higher equilibrium investment in the Tullock contest.

1. Set of Equilibria and Expected Value of Winning the Entry Contest

\section{A Pooling Equilibria}

It is easy to see that pooling at the campaign stage can always be supported as an equilibrium. It requires the following ingredients:

1 The candidates in the general election make the same promises, $P_{H}=P_{L}$, in their election campaigns.

2 The voters vote for each candidate with probability $\frac{1}{2}$. Any candidate promising a different amount is not voted for. This is justified by the outof-equilibrium belief that such a candidate is a low type. 
3 The winner $i$ of the election will transfer

$$
T_{i}= \begin{cases}\left(1-\frac{1}{\beta_{i}}\right) P_{i} & \text { if } \beta_{i}>1 \\ 0 & \text { if } \beta_{i} \leq 1\end{cases}
$$

to the voters.

Expression (5) follows directly from maximizing (3) with respect to the transfer. It is easy to see that nobody has an incentive to deviate. Note that high types are worse off than low types in all pooling equilibria except for the equilibrium with pooling on a promise of zero. In this case no lying occurs and both types' expected value from winning the entry contest is the same. However, it is a knife-edge case that is not robust to minimal deviations from the specified out-of-equilibrium beliefs. If voters attach a minimal probability to the event that a promise greater than zero comes from a high type, the pooling equilibrium with zero promises collapses.

\section{B Separating Equilibria}

Note, that there cannot be separating equilibria at the campaign stage in which the high types promise more. If such a strategy profile was played, low types could always benefit from deviating and mimicking the high types. However, for some parameter settings there are equilibria with separation at the campaign stage in which the low types promise more than the high types, such that the transfer that a voter can expect to receive after seeing a high promise (from a low type) exceeds that after a low promise (which requires that $\beta_{L}>0$ ). High types only win with positive probability if they compete against another high type and the difference in promises of high and low types is large enough to make a deviation from their low promise unprofitable. The existence of these equilibria for some parameter settings has already been proved in Corazzini et al. (2014) who study the same game without an entry stage. Both transfers in these equilibria have to be strictly positive, as a high type would otherwise benefit from deviating and promising $\epsilon>0$ instead of zero which would guar- 
antee her victory against another high type. Note that low types must be strictly better off in this type of equilibrium. If high types were better or equally well off, low types would have an incentive to deviate an mimick the high type's promise. This would neccessarily make them strictly better off because of their lower lying costs.

\section{Optimal Investments}

First, we show that the type with the higher expected value from winning the contest will invest more and, second, that the equilibrium investments are unique for given valuations.

\section{A Higher Expected Value - Higher Investment}

We now determine the optimal levels of investment in the entry contests. We can do this for all contest success functions $\rho\left(I_{1}, I_{2}\right)$ that have the following standard properties: $\rho_{1}^{\prime}>0, \rho_{2}^{\prime}<0, \rho_{1}^{\prime \prime}<0$ and $\rho_{2}^{\prime \prime}>0$, where $\rho_{1}^{\prime}\left(\rho_{2}^{\prime}\right)$ represents the first derivative with respect to the first (second) argument in the function. Note that the Tullock contest success function belongs to this category.

The potential candidates do not have to be concerned about their bid in the entry contest sending a signal to the electorate. Therefore the candidates' objective functions at the candidate entry stage can be written in the following compact form:

$$
\begin{aligned}
E\left[U_{k}\right] & =E_{I_{l}}\left[\rho\left(I_{k}, I_{l}\right)\right] E V_{k}-I_{k} \\
E\left[U_{k}\right] & =\left[\phi \rho\left(I_{k}, I_{H}\right)+(1-\phi) \rho\left(I_{k}, I_{L}\right)\right] E V_{k}-I_{k},
\end{aligned}
$$

where $k, l=1,2 ; k \neq l$ and $I_{k}$ and $I_{l}$ are the amounts invested in the entry competition. The values $I_{H}$ and $I_{L}$ reflect the investments of an individual with high and low lying aversion respectively. We recall that $E_{I_{l}}$ stands for the 
expectation taken over $I_{l}$. The entry contestants' first-order conditions are

$$
E_{I_{l}}\left[\rho_{1}^{\prime}\left(I_{k}, I_{l}\right)\right] E V_{k}=1
$$

In this case, a candidate with low lying aversion and hence $E V_{L}$ will invest more in the entry competition. Formally, using the implicit function theorem we obtain

$$
\frac{d I_{1}}{d E V_{1}}=-\frac{E_{I_{2}}\left[\rho_{1}^{\prime}\left(I_{1}, I_{2}\right)\right]}{E_{I_{2}}\left[\rho_{1}^{\prime \prime}\left(I_{1}, I_{2}\right)\right] E V_{1}}>0
$$

Using (8), the equilibrium entry contest investments of low and high types are characterised by

$$
\begin{aligned}
\left(\phi \rho_{1}^{\prime}\left(I_{L}, I_{L}\right)+(1-\phi) \rho_{1}^{\prime}\left(I_{L}, I_{H}\right)\right) E V_{L} & =1 \\
\left(\phi \rho_{1}^{\prime}\left(I_{H}, I_{L}\right)+(1-\phi) \rho_{1}^{\prime}\left(I_{H}, I_{H}\right)\right) E V_{H} & =1
\end{aligned}
$$

\section{B Unique Optimal Bids}

We now show that there is a unique optimal investment pair $\left(I_{L}, I_{H}\right)$ in the entry competition game when using a Tullock contest success function. First note that it follows from $E_{I_{2}}\left[\rho_{1}^{\prime \prime}\left(I_{1}, I_{2}\right)\right]<0$ that the objective of the potential candidates are concave and hence they have a unique solution to their expected utility maximization problem.

With the Tullock contest success function the politicians maximize

$$
E U_{i}=\left(\phi \frac{I}{I+I_{H}}+(1-\phi) \frac{I}{I+I_{L}}\right) E V_{i}-I
$$


The equilibrium conditions as given in (10) and (11) can now be written as

$$
\begin{aligned}
& \left(\phi \frac{1}{4 I_{H}}+(1-\phi) \frac{I_{L}}{\left(I_{H}+I_{L}\right)^{2}}\right) E V_{H}=1 \\
& \left(\phi \frac{I_{H}}{\left(I_{L}+I_{H}\right)^{2}}+(1-\phi) \frac{1}{4 I_{L}}\right) E V_{L}=1
\end{aligned}
$$

We have seen previously that ceteris paribus, the individual with the higher prize when winning the contest will spend more. In the equilibria characterized ed above, we have $E V_{L}>E V_{H}$. That is, the politician of low lying aversion type values standing for election more than the individual with high lying aversion. Consequently, we must have that $I_{L} \geq I_{H}$. To simplify the equilibrium conditions, we use $I_{L}=\psi I_{H}$ with $\psi \in[0,1]$. Inserting into the equilibrium conditions and solving for $I_{L}$, we obtain

$$
\begin{gathered}
I_{L}=E V_{H}\left(\frac{\phi}{4 \psi}+\frac{1-\phi}{(1+\psi)^{2}}\right):=I_{u}(\psi) \\
I_{L}=E V_{L}\left(\frac{\phi \psi}{(1+\psi)^{2}}+\frac{1-\phi}{4}\right):=I_{b}(\psi)
\end{gathered}
$$

Optimal investments are given by the intersection between $I_{u}(\psi)$ and $I_{b}(\psi)$. With respect to the functions' properties,

- it is obvious that $I_{u}(\psi)$ is strictly decreasing with $\psi$. Over the domain $\psi \in[0,1], I_{u}$ declines from $\lim _{\psi \rightarrow 0} I_{u}(\psi)=\infty$ to $I_{u}(1)=\frac{E V_{H}}{4}$.

- the curvature of $I_{b}(\psi)$ is governed by the expression $\frac{\psi}{(1+\psi)^{2}}$. For the derivative with respect to $\psi$ we obtain

$$
\frac{\partial}{\partial \psi}=\frac{1-\psi}{(1+\psi)^{3}} \geq 0, \forall \psi \in[0,1] .
$$

Hence, $I_{b}(\psi)$ increases over its domain from $I_{b}(0)=(1-\phi) \frac{E V_{L}}{4}$ to $I_{b}(1)=\frac{E V_{L}}{4}$.

Since $E V_{L}>E V_{H}$, there exists a unique intersection of $I_{u}(\psi)$ and $I_{b}(\psi)$ on $[0,1]$ and hence a unique pair $\left(I_{L}, I_{H}\right)$ of entry competition investments. 
Consequently, there are unique investment levels in the closed entry contest for the high type $I_{H}$ and the low type $I_{L}$.

This concludes the proof.

\section{Proposition 2. [Transparent Entry]}

Consider the political game with transparent entry contest.

(a) For all admissible parameter values, there are Symmetric Perfect Bayesian Equilibria in which both types of politicians pool and invest the same amount in the entry contest.

(b) There are also Symmetric Perfect Bayesian Equilibria in which low types invest strictly more in the entry contest than high types. However, these separating equilibria do not exist for all admissible parameter values.

Proof. We start with part (a).

(a) Similar to the opaque entry case it is easy to show that pooling can always be supported as an equilibrium. Now pooling also includes the investment stage. It requires the following ingredients:

1 The different types of politicians make the same investments, $I_{L}=I_{H}$, in the entry contest.

2 The candidates in the general election make the same promises, $P_{H}=P_{L}$, in their election campaigns.

3 The voters vote for each candidate with probability $\frac{1}{2}$. Any candidate investing or promising a different amount is not voted for. This is justified by the outof-equilibrium belief that such a candidate is a low type. 
4 The winner $i$ of the election will transfer

$$
T_{i}= \begin{cases}\left(1-\frac{1}{\beta_{i}}\right) P_{i} & \text { if } \beta_{i}>1 \\ 0 & \text { if } \beta_{i} \leq 1\end{cases}
$$

to the voters.

It is easy to see that such an equilibrium always exist if we set $I_{L}=I_{H}=\epsilon$ and $P_{L}=P_{H}=B$. In this case, nobody can invest less and investing more automatically leads to a loss at the election stage because the candidate of the other party will have invested $\epsilon$.

(b) Separation can now occur either at the entry or at the campaign stage with the obvious consequence that if there is separation at one stage, there is no reason anymore to pool at the other. The equilibria in which separation originates from the campaign stage are the same as those under opaque entry. Their existence requires that $\beta_{L}>1$. Otherwise, low types will never be elected as they would transfer zero and they can be identified in a separating equilibrium. However, there is a different type of separating equilibria in which separation originates from the entry stage. If the share of high tpes $\phi$ is close to zero, there can be a separating equilibrium in which high types invest $\epsilon$ and low types the optimal investment with separation $I_{L}$ which will be arbitrarily close to the optimal investment when playing against another low type with certainty. In this case, they will win the entry contest with a very high probability and also meet another low type at the election stage with a high probability. As a consequence, they will win with a probability close to one half which is clearly better than mimicking the high types. Deviation from high types is prevented by the out-of-equilibrium belief of voters that anyone investing more than $\epsilon$ is a low type. We will now show that these equilibria do not exist for all admissible parameters. Note that we can make the expected value of winning the entry contest for a low type $E V_{L}$ arbitrarily small, and smaller than $\epsilon$, by setting $\phi$ very close to one. If $\phi$ is close to 1 , a low type meets a high type at the election stage with a 
probability close to one and looses. If $E V_{L}$ is close to zero, the only chance for a separating equilibrium is an investment that is even smaller. However, there is the lower bound of $\epsilon$ for the investment that prevents an arbitrarily small investment.

\section{A2. Optimal Entry Contest Investments in the Experiment}

In the experiment, we controlled for income effects by enforcing the entry contest investment with a probability of $\frac{1}{2} \cdot{ }^{18}$ Knowing this probability ex ante, the politicians take it into account when deciding on their entry bids. To calculate the predicted entry contest investments in the experiment, our previous theoretical results can still be used directly when interpreting $E V$ as being twice its actual value. ${ }^{19}$ We have all the parameters except for the levels of lying aversion $\beta_{L}$ and $\beta_{H}$ to determine the optimal entry bids. In the following, we give some plausible value ranges by assuming the high type to possess $\beta_{H}=1000$ and $\beta_{L}=0$. Note that the optimal transfer (for $\beta_{i}>0$ ) takes the form $T_{i}=\left(1-\frac{1}{\beta_{i}}\right) P_{i}$ and, hence, $\frac{1}{\beta_{i}}$ can directly be interpreted as the share the politicians keep for themselves (for $\beta_{i} \leq 1$ it is, of course, 1). For $\beta_{H}=1000$, the high lying averse type would only keep $1 / 1000$ for herself and give $99.9 \%$ of the promised amount to the voters. If $\phi=0.5$ and types pool an the maximum promise $B$, a low type politician without any lying costs at all $\left(\beta_{i}=0\right)$ would spend 59 points in an opaque entry contest and the high type with $\beta_{H}=1000$ would invest 9 when playing against such a low type. The maximum bid that we can produce as an equilibrium prediction in our model is that of a low type with zero costs of lying if there are (almost) no high types. In this case the low type would (almost) bid one fourth of the prize for winning the contest multiplied by two because the investment only has to be paid with probability one half. This amounts to 80 points. To broadly delineate the range of bids we have chosen extreme values for $\beta_{i}$. With more moderate values of lying aversion, the bids will be between these extreme values. In a transparent

\footnotetext{
${ }^{18}$ We refer to income effects when higher investments in the entry contest directly leading to lower transfers to compensate for the amount spent in the entry contest but not because of the higher expected value from holding office.

${ }^{19}$ Note that this is equivalent to adjusting the politicians' objective functions by multiplying the entry contest investments by $\frac{1}{2}$.
} 
entry contest, investments in the range 1 (the minimum investment in the experiment) to 80 can be rationalized via the separating equilibria described in the proof of Proposition 2.

\section{A3. Additional Tables and Figures}

Table A1: Opaque Entry: Promises and Beliefs

\begin{tabular}{lcccccc}
\hline \hline & \multicolumn{2}{c}{ all } & \multicolumn{2}{c}{ paid } & \multicolumn{2}{c}{ not paid } \\
\hline Diff. in Promises & 0.125 & $(0.085)$ & 0.076 & $(0.141)$ & $0.172^{* *}$ & $(0.054)$ \\
_cons & -3.409 & $(1.769)$ & -1.649 & $(1.396)$ & -4.738 & $(2.374)$ \\
\hline$N$ & 1320 & 591 & 729 & \\
$R^{2}$ & 0.01 & 0.00 & 0.01 & \\
N_clust & 6 & 6 & 6 & \\
\hline \hline
\end{tabular}

Note: OLS Models with difference in beliefs regarding candidate generosity (differences in transfers) as dependent variable. Standard errors in parentheses are adjusted for clustering at the session level. Levels of significance: ${ }^{*} \mathrm{p}<0.10,{ }^{*} \mathrm{p}<0.05,{ }^{* * *} \mathrm{p}<0.01$.

Table A2: Opaque Entry: Promises and Transfers

\begin{tabular}{lcccccc}
\hline \hline & \multicolumn{2}{c}{ all } & \multicolumn{2}{c}{ paid } & \multicolumn{2}{c}{ not paid } \\
\hline Promise & $0.206^{* * *}$ & $(0.040)$ & 0.079 & $(0.098)$ & $0.315^{* *}$ & $(0.104)$ \\
${ }^{\prime}$ cons & $64.981^{* * *}$ & $(14.288)$ & $84.117^{* *}$ & $(22.637)$ & 47.568 & $(28.505)$ \\
\hline$N$ & 880 & & 394 & 486 & \\
$R^{2}$ & 0.01 & 0.00 & 0.01 & \\
N_clust & 6 & 6 & 6 & \\
\hline \hline
\end{tabular}

Note: OLS Models with transfers as dependent variable. Standard errors in parentheses are adjusted for clustering at the session level. Levels of significance: $* \mathrm{p}<0.10, * *$ $\mathrm{p}<0.05, * * * \mathrm{p}<0.01$. 
Table A3: Transparent Entry: Investments, Promises, and Beliefs

\begin{tabular}{lcccccc}
\hline \hline & \multicolumn{2}{c}{ all } & \multicolumn{2}{c}{ paid } & \multicolumn{2}{c}{ not paid } \\
\hline Diff. in Investments & $-0.447^{* * *}$ & $(0.093)$ & $-0.684^{* *}$ & $(0.191)$ & $-0.287^{* * *}$ & $(0.067)$ \\
Diff. in Promises & $0.206^{*}$ & $(0.089)$ & $0.232^{* *}$ & $(0.088)$ & 0.176 & $(0.092)$ \\
_cons & 2.916 & $(1.962)$ & 0.760 & $(4.761)$ & $4.567 * *$ & $(1.492)$ \\
\hline$N$ & 1320 & & 633 & & 687 & \\
$R^{2}$ & 0.04 & & 0.09 & 0.02 & \\
N_clust & 6 & & 6 & 6 & \\
\hline \hline
\end{tabular}

Note: OLS Models with difference in beliefs regarding candidate generosity (differences in transfers) as dependent variable. Standard errors in parentheses are adjusted for clustering at the session level. Levels of significance: $* \mathrm{p}<0.10, * * \mathrm{p}<0.05, * * * \mathrm{p}<0.01$.

Table A4: Transparent Entry: Investments, Promises, and Transfers

\begin{tabular}{|c|c|c|c|c|c|c|}
\hline \multirow[b]{2}{*}{ Investment } & \multicolumn{2}{|c|}{ all } & \multicolumn{2}{|c|}{ paid } & \multicolumn{2}{|c|}{ not paid } \\
\hline & -0.763 & $(0.468)$ & $-0.917^{*}$ & $(0.448)$ & -0.652 & $(0.502)$ \\
\hline Promise & 0.253 & (0.134) & $0.310^{*}$ & $(0.136)$ & 0.181 & $(0.202)$ \\
\hline _cons & $99.102 *$ & $(42.136)$ & $95.477 * *$ & (35.267) & 109.243 & (57.191) \\
\hline$N$ & 880 & & 422 & & 458 & \\
\hline$R^{2}$ & 0.04 & & 0.06 & & 0.03 & \\
\hline N_clust & 6 & & 6 & & 6 & \\
\hline
\end{tabular}

Note: OLS Models with transfers as dependent variable. Standard errors in parentheses are adjusted for clustering at the session level. Standard errors in parentheses are adjusted for clustering at the session level. Levels of significance: ${ }^{*} \mathrm{p}<0.10,{ }^{* *} \mathrm{p}<0.05, * * * \mathrm{p}<0.01$. 
Figure A1: Perceived Honesty in Different Professions

Please tell me how you would rate the honesty and ethical standards of people in these different fields -- very high, high, average, low or very low?

Dec. $2-6,2015$

\% Very high/High

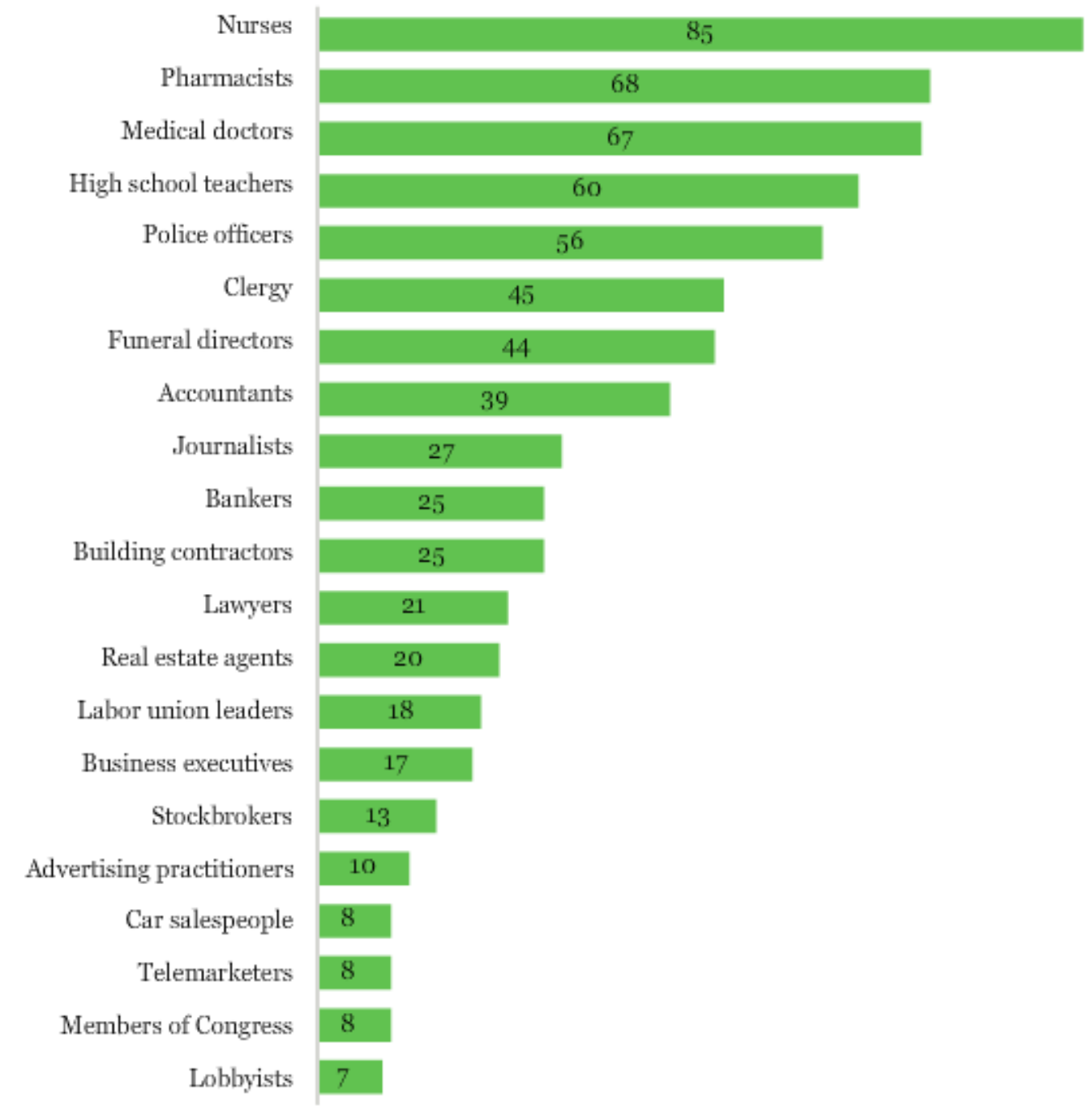

GALLUP'

Source: http://www.gallup.com/poll/1654/honesty-ethics-professions.aspx?version=print (accessed on Sep 24, 2016) 


\section{A4. Instructions to the Experiment}

We present translated instructions to the experiment. As the instructions for the opaque and transparent treatments are very similar, we combined them. The segments that were different for the transparent treatment appear in double brackets. The original German instructions can be obtained from the authors upon request. 


\section{Overview}

Welcome to this Experiment. We ask you not to talk to the other participants during the course of the experiment and to switch off your cell phone and all other mobile devices.

For the participation in this session, you will be paid in cash at the end of the experiment. The payment will depend partly on your decisions, partly on the decisions of the other players and partly on chance. For this reason, it is important that you understand the instructions before the experiment starts.

In this experiment, all interactions between the participants run through the computer in front of you. You will interact anonymously. Neither your name nor the names of the other participants will be disclosed. Also for the analysis only anonymized data will be used.

The present session consists of several rounds. At the end of the experiment, one round will be randomly selected and paid. The rounds that will not be selected will not be paid. Your payment consists of the points that you earn in the selected round, exchanged into Euro, and a lump sum payment of 3 Euro. The exchange rate from points to Euro is as follows. Every point has a value of $\mathbf{2 0}$ Cents, which means:

$$
5 \text { point }=1.00 \text { Euro. }
$$

Every participant will be paid in private in such a way that the other participants cannot see how much you will have earned. 


\section{Experiment}

This experiment consists of $\mathbf{2 0}$ rounds, which are identical in their course of action.

\section{The roles and the group}

In every round you are in the same role. Either you are a politician or a voter. Your role will be randomly determined at the beginning of the first round.

In every round 3 voters and 4 politicians will be matched in a group of 7 participants, i.e., in every round you play in a newly composed group.

All interactions in a round will take place within your group.

\section{Overview}

In this experiment, a politician will be elected who can decide how many points to distribute to the voters. The election has two stages. First, there is an entry contest, in which two politicians are determined who will run for office. Then, these two politicians make an election promise. The voters are informed about the election promise [[and about the investment of the politicians in the entry contest]] and can vote for one of the politicians.

\section{The entry contest}

The 4 politician in a group are randomly matched into two parties, party $\mathbf{A}$ and party $\mathbf{B}$, such that in each party there are $\mathbf{2}$ politicians. At the beginning, all politician receive a budget of 100 points.

The two politicians of a party compete in an entry contest in order to become candidate of the party in the following election. Both politicians invest a number of points between 1 and 100 in order to become candidate (see Figure 1). If you are a politician then the probability $\mathrm{P}$ to win the entry contest depends on your investment and on the investment of the other politician. The probability results from the following formula:

$$
P=\frac{\text { your investment }}{\text { your investment }+ \text { investment of the other politician }}
$$


For example, if you invest $\mathrm{x}$ and the other politician of your party invests twice as much, $2 \mathrm{x}$, then the probability that you win the entry contest equals one third and the probability that the other wins equals two thirds.

When all politicians made their investment, the probabilities to win the entry contest are set and by drawing a random number for each party, the computer determines the actual winners according to these probabilities.

In addition, the computer decides whether the investments in this round have to be paid by drawing a random number. The probability that the investments have to be paid equals $50 \%$. If the computer decides that the investment has to be paid then all politicians have to pay their investment, also the losers of the entry contest of their parties.

\section{Figure 1. Screen of the entry contest}

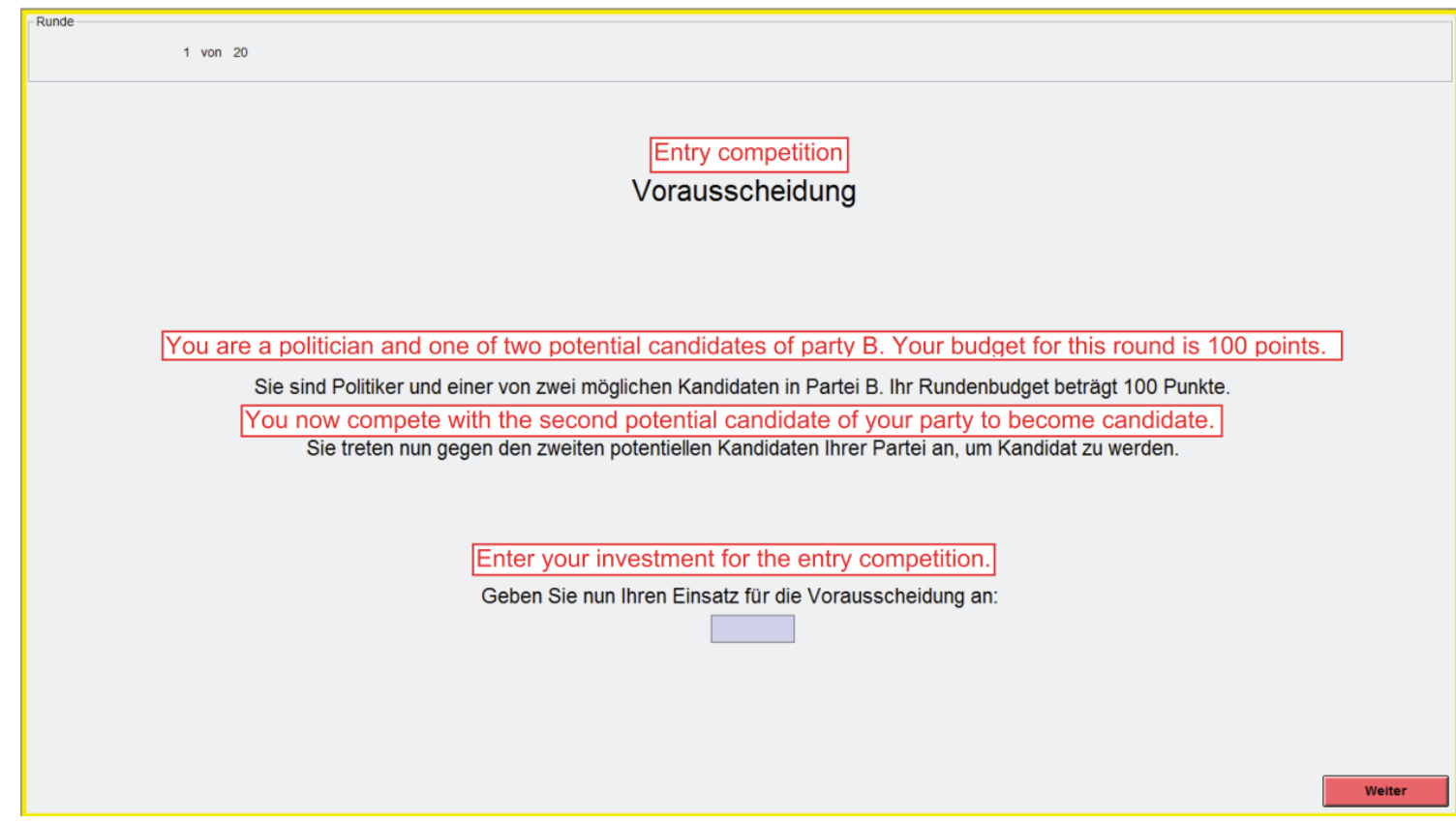

\section{The election and the distribution of points}

After the entry contest the politicians answer two estimation questions on the screen, which have no influence on the payment.

On the next screen (see Figure 2) the politicians are informed whether they have to pay the investment in the entry contest or not. They are not yet informed about whether they won or not. They have to make an election promise to the voters for the case that they won and are 
candidate of their party, and run for office against the candidate of the other party. In the promise they declare how many points they will transfer to the voter if they win. It is not possible to discriminate between the voters, i.e. the promise has to be the same for all voters.

\section{Figure 2. Screen for the election promise}

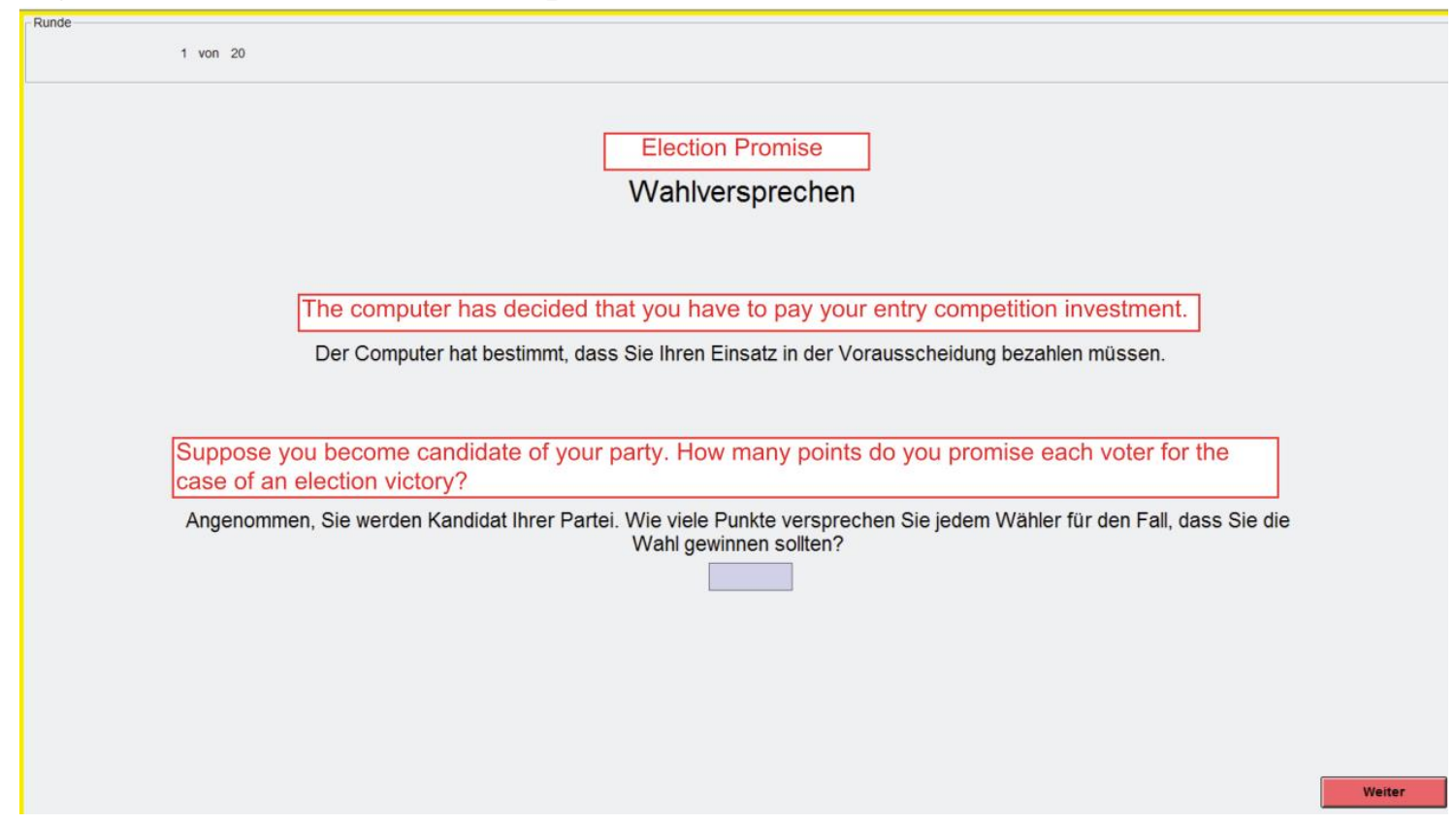

After the submission of the election promise, the politicians answer an estimation question, which has no impact on the payment.

Then, the voters are informed about the promise of the candidates[[, and their investment in the entry competition]]. Then the voters vote (for the details, see below).

The winner of the election receives 50 points, which will be part of the payment of the round, in addition to the remaining points of the round budget after the entry competition. In addition, the winner receives $\mathbf{2 7 0}$ points, which he can distribute between the voters and himself. Thus, the maximum that he can distribute to each voter equals 90 points, the minimum equals 0 points. As in the case of the promise, it is not possible to discriminate between the voters, i.e., all voters have to receive the same number of points.

How the points are distributed is entered on the screen in Figure 3. The politicians make this decision under the assumption that they win before they know whether they actually won. They distribute the $\mathbf{2 7 0}$ points between them and the voters. The winner will only be announced at the end of the round. This is also when the distribution of the winner will be implemented. 


\section{Figure 3. Screen for the point distribution}

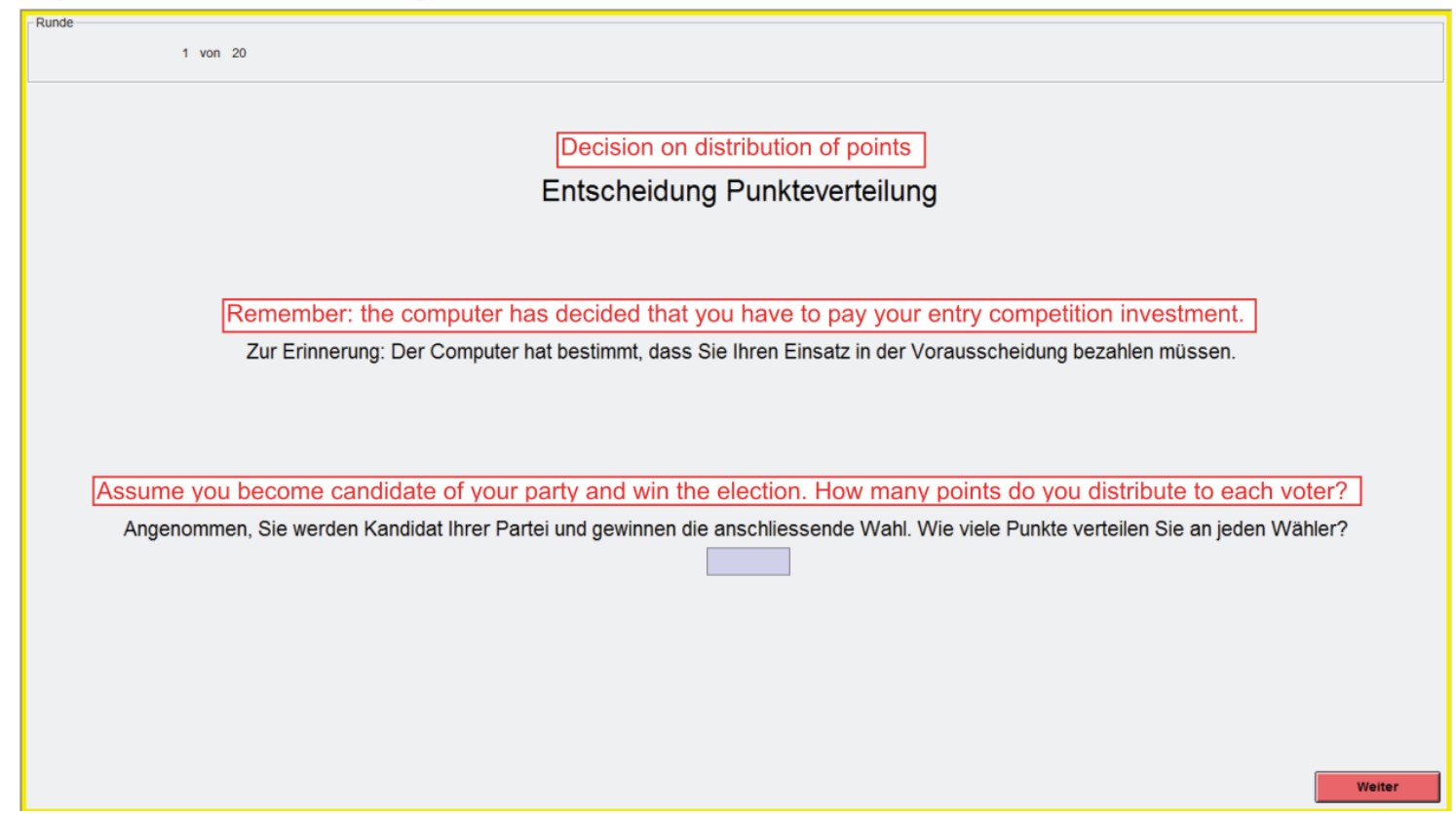

\section{The voters and the election}

At the start of each round, the voters receive an endowment of 50 points, which they receive in any case in this round. At first, the voters have to wait for the entry contest and the election promise of the politicians. When the candidates of the parties are determined, the voters are informed about the election promises of the politicians. In addition, they are informed [[about the investment of the candidates in the entry contest and]] about whether the candidates have to pay the investment or not.

Then, they can either vote for the candidate of party A or for the candidate of party B (Figure 4). The winner of the election is determined by majority vote, i.e. the candidate who receives 2 or 3 votes of the 3 voters is the winner and his distribution of the points will be implemented.

After the election the voters answer two estimation questions, which do not affect the payments. 


\section{Figure 4. Screen for voting}

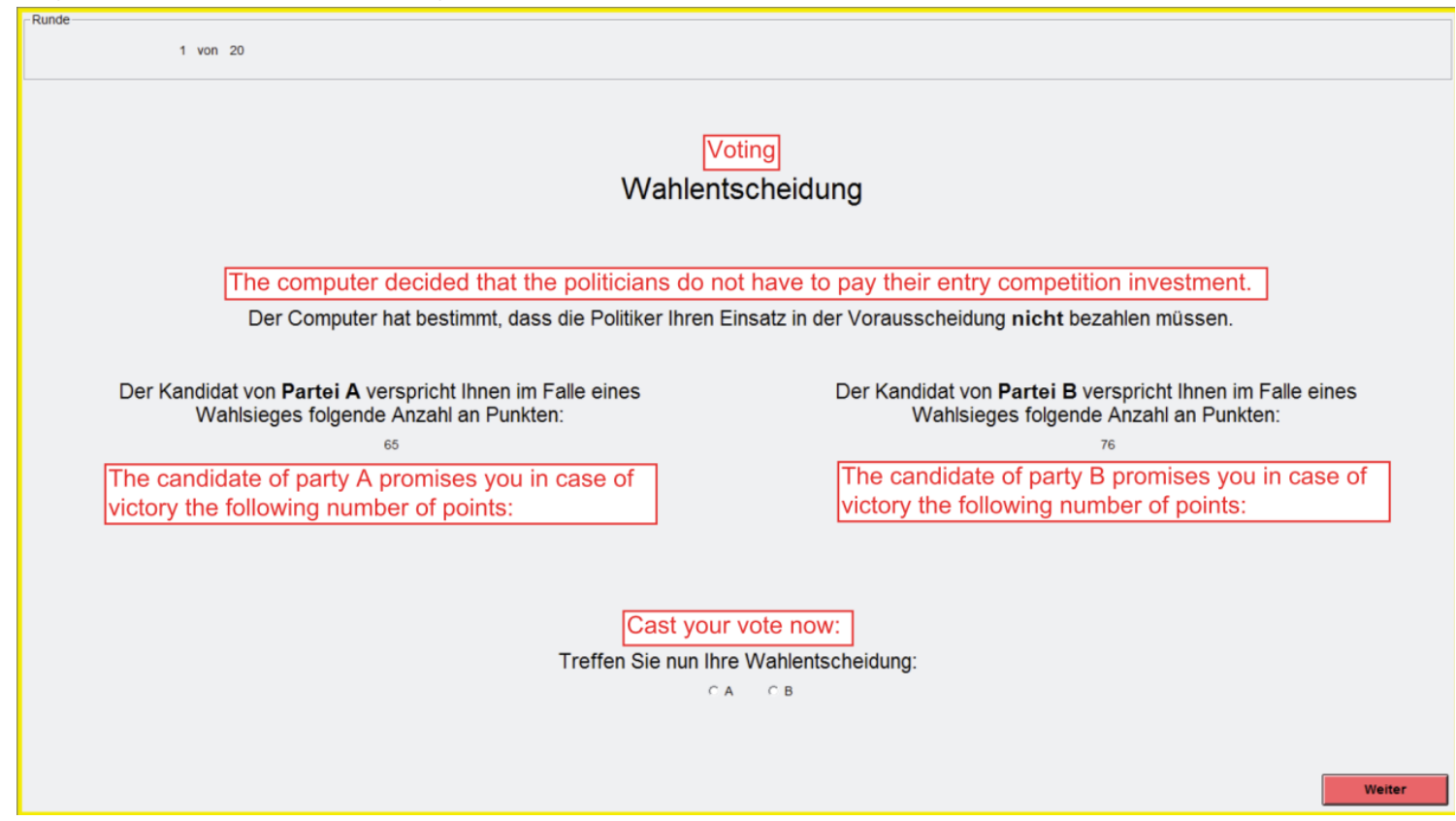

\section{Feedback and payment of the round}

After the election, the winner is determined and thus also the payment of the round for all group members. On the last screen you are informed about your decision in this round and in addition, you receive feedback about the decisions of all group members.

For a voter the round payment is as follows:

Start endowment of 50 points

+ number of points that the winner distributes to all voters

For a politician who does not win the election, the round payment is as follows:

Budget of 100 points

- Investment in the entry contest if it has to be paid

For a politician who wins the election, the round payment is as follows:

Budget of 100 points

- Investment in the entry contest if it has to be paid

+50 points for winning the election

+270 point that can be distributed

$-3 *$ Number of points that are distributed to each voter 


\section{Final payment}

Reminder: At the end of the experiment one round will be randomly selected; the income in this round will be exchanged from points into Euro and paid in private. The rounds that are not selected are not paid.

On the last screen of the last round, you are informed about which round was selected and how much you earn in Euro.

\section{Questions?}

Take your time to carefully go over the instruction again. If you have a question, please raise your hand. An experimenter will come to your cubicle.

When you think you understand everything well, you can start with the quiz on the screen. This quiz is only used to ensure that everybody understands the instructions. The answers do not affect your payment. 
On screen control questions

Quiz: Please answer the following questions on the instructions. The solution follows on the next screen.

1. How many rounds will be played?

$$
\begin{array}{ll}
\circ & 1 \\
\circ & 10 \\
\circ & 20
\end{array}
$$

2. Assume you are politician and invest 10 points in the entry contest. Assume the other politician invests 15 points. What is the probability that you win the entry contest?
○ $10 \%$
○ $40 \%$
○ $50 \%$

3. Assume you are politician and invest 10 points in the entry contest. Assume the other politician invests 40 points. What is the probability that you win the entry contest?
○ $10 \%$
○ $20 \%$
○ $50 \%$

4. The politician who won the election invested 30 points in the entry contest. He has to pay the investment. He decided to distribute 60 points to every voter.

a) What is the payment in points for the winner?
○ 120
○ 180
○ 210

b) What is the payment in points for the losing politician who invested 20 points in the entry contest?
○ 80
○ 90
○ 100

c) What is the payment in points for a voter?
○ 90
$\circ 110$
○ 120

5. The politician who won the election invested 20 points in the entry contest. He does not have to pay the investment. He decided to distribute 75 points to every voter.

a) What is the payment in points for the winner?
○ 150
○ 195
○ 215

b) What is the payment in points for the losing politician who invested 10 points in the entry contest?
○ 80
○ 90
○ 100

c) What is the payment in points for a voter?

○ 75

○ 115

○ 125 